\title{
DISTRIBUIÇÃO ESPAÇO-TEMPORAL DOS DIAGNÓSTICOS LABORATORIAIS DA RAIVA ANIMAL
}

\section{SPACE-TIME DISTRIBUTION OF LABORATORY DIAGNOSIS OF ANIMAL RABIES}

\author{
Laura Helena Marcon Teixeira ${ }^{1}$ \\ Leonardo Aparecido Guimarães Tomaz ${ }^{2}$ \\ Guido Fontgallad Coelho Linhares ${ }^{3}$ \\ Marli Francisca Cândida Santos ${ }^{4}$ \\ Valéria de Sá Jayme ${ }^{3}$
}

\begin{abstract}
1Professora Doutora da Universidade Estadual de Goiás, Quirinóplois, GO, Brasil - lamarc@gmail.com 2Médico Veterinário, Doutor, Fiscal da AGRODEFESA, Goiânia, GO, Brasil 3Professores Doutores da Universidade Federal de Goiás, Goiânia GO, Brasil 4Médica Veterinária, Especialista, Fiscal da AGRODEFESA, Goiânia, GO, Brasil
\end{abstract}

\section{Resumo:}

A raiva é uma enfermidade infectocontagiosa que afeta mamíferos, inclusive o homem. Estima-se que a raiva dos herbívoros seja responsável por enormes prejuízos econômicos na América Latina. O morcego hematófago Desmodus rotundus é o principal transmissor do vírus rábico (VR). Este estudo teve como objetivo avaliar a evolução do diagnóstico laboratorial para raiva animal em cinco espécies animais, na série cronológica 1990-2010, na microrregião Quirinópolis, Goiás, Brasil. Para avaliação da distribuição dos casos diagnosticados foram utilizados resultados de diagnóstico laboratorial, realizados pelo Laboratório de Diagnóstico da Agência Goiana de Defesa Agropecuária. A partir destes, foi construído um banco de dados com as variáveis: município de origem do animal, resultado, mês e ano. Das 116 amostras analisadas, 9\% (10) foram positivas para oVR e 91\% (106) negativas. Todos os resultados positivos foram provenientes de bovinos. Dentre os municípios da microrregião, Itarumã apresentou maior número de casos positivos e Caçu enviou mais amostras. Houve tendência de aumento no envio de amostras e no número de exames laboratoriais. Também houve tendência ao aumento de diagnósticos positivos. Amostras da espécie bovina foram as mais analisadas, seguida de morcegos hematófagos. Em relação à época do ano, foram observados mais casos positivos no período da seca.

Palavras-chave: Animais domésticos; epidemiologia; quirópteros; vírus rábico.

\begin{abstract}
:
Rabies is an infectious contagious disease that affects mammals, including humans. Herbivore rabies is estimated to be the cause of major economic downturns in Latin America. The hematophagous bat Desmodusrotundus is the main transmitter of the rabies virus. The present study aimed at evaluating the laboratory diagnosis of animal rabies in five species of animals, in the 1990-
\end{abstract}


2010 period, in the microregion of Quirinópolis, Goiás, Brazil. In order to evaluate the distribution of the animal rabies diagnosed cases, we used disease data from the laboratory diagnosis, performed by the Diagnosis Laboratory of the Goiás Agency for Agriculture and Cattle Breeding Defense. A databank was developed with city variables, namely animal origin, result, month and year. Out of the 116 analyzed samples, 9\% (10) showed to be positive for the rabies virus and 91\% (106) were negative. All the positive results were found in cattle. Among the surveyed cities, Itarumã showed the highest number of positive cases and Caçu submitted most samples. Both sample submission and laboratory exams tended to be higher. Positive diagnosis tended to be higher. Most of the analyzed samples came from cattle, followed by the hematophagous bats. The distribution of positive cases in relation to the time of the year was higher in the period of drought.

Keywords: bats; chiropterans; epidemiology; livestock.

Recebido em: 29 jul. 2014.

Aceito em: 10 nov. 2014

\section{Introdução}

A raiva é considerada uma das zoonoses de maior importância em Saúde Pública, não só por sua evolução letal, como também por seu elevado custo social e econômico. É uma antropozoonose conhecida desde os tempos remotos, caracterizada por uma encefalomielite aguda fatal nos animais e no ser humano ${ }^{(1)}$.

Estima-se que a raiva dos herbívoros seja responsável por enormes prejuízos econômicos diretos na América Latina, da ordem de 30 milhões de dólares/ano, sendo que no Brasil este valor se aproxima de 15 milhões de dólares, com a morte de cerca de 40.000 cabeças de gado/ano ${ }^{(2)}$, além dos gastos indiretos que podem ocorrer com a vacinação de milhões de bovinos e inúmeros tratamentos pósexposição (sorovacinação) de pessoas que mantiveram contato com animais suspeitos.

Os principais reservatórios da raiva na América Latina são os cães e os morcegos. No caso dos herbívoros, o morcego Desmodus rotundus (E. Geoffroy, 1810) é o principal transmissor do vírus rábico (VR). Este morcego é hematófago obrigatório e se alimenta exclusivamente de sangue de mamíferos e aves. No entanto, considerando que o controle da raiva entre os animais urbanos (cães e gatos) vem sendo cada vez mais eficiente e que as medidas na área rural junto aos animais de interesse econômico também vêm se aprimorando, os animais silvestres e os sinantrópicos assumem um papel de extrema importância como reservatórios naturais do $\mathrm{VR}^{(3)}$.

Os vírus do gênero Lyssavirus estão compreendidos em sete genótipos, conforme a mais recente resolução do Comitê Internacional sobre Taxonomia de Vírus (ICTV), havendo sido propostos outros quatro genótipos ${ }^{4}$. No Brasil, Heinemann et al. ${ }^{(2)}$ identificaram duas variantes de vírus rábico, uma do ciclo silvestre, isolada de morcegos e bovinos (variante 3) e outra do ciclo urbano, isolada de cães (variante 1), não havendo diferenças entre os isolamentos de bovinos e os de $D$. rotundus.

No Brasil, a raiva dos herbívoros pode ser considerada endêmica dependendo da região. Entre os fatores que contribuem para a disseminação da raiva nos herbívoros, observam-se as alterações dos habitats dos morcegos e oferta de alimento, devido à ocupação desordenada dos ambientes pela ação antrópica ${ }^{(2)}$. 
Neste contexto, o presente estudo teve como objetivo avaliar a evolução do diagnóstico laboratorial para a raiva animal em cinco espécies animais (bovinos, equinos, suínos, morcegos hematófagos e não hematófagos) na série cronológica 1990-2010 na microrregião Quirinópolis, Goiás.

\section{Material e Métodos}

A microrregião Quirinópolis está localizada na região Centro-Oeste do Brasil, mesorregião Sul Goiano, a sudoeste do estado de Goiás. É a microrregião de $\mathrm{n}^{\circ} 18$, formada pelos seguintes municípios: Quirinópolis, Gouvelândia, Cachoeira Alta, Caçu, Itarumã, Paranaiguara, Itajá, São Simão e Lagoa Santa (FIGURA 1). Possui uma área total de 16.068,103 km² e situa-se às margens do lago de São Simão, no rio Paranaíba, distante 280 km de Goiânia.

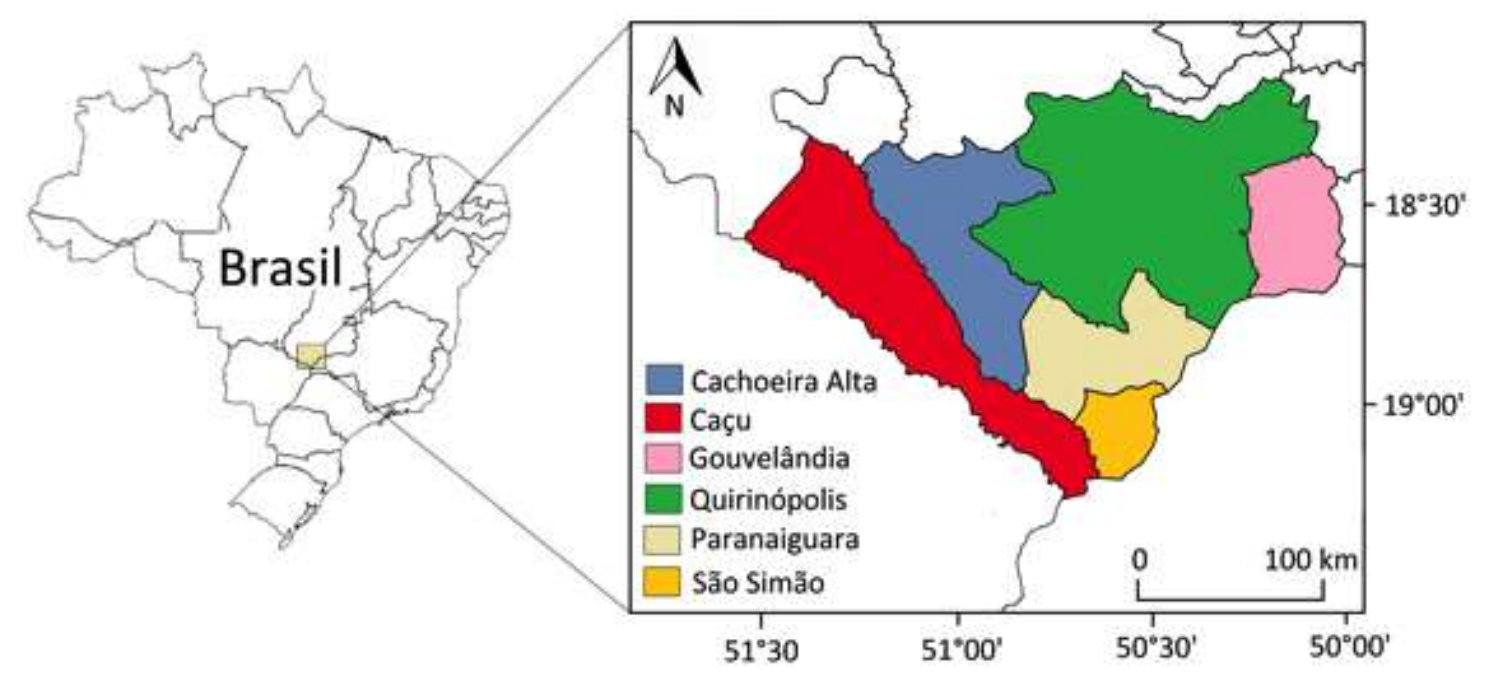

Figura 1: Microrregião Quirinópolis inserida na região sudoeste do estado de Goiás ${ }^{5}$

Essa microrregião possui predominância de mais de 95\% do Bioma Cerrado, caracterizada por verões chuvosos (outubro a março) e invernos secos (junho a setembro) e de clima tropical chuvoso. Atualmente, encontra-se em elevado estágio de degradação, com considerável parte dessa paisagem ocupada pela produção agrícola de monocultora em grande escala e pecuária moderna, além da implementação de empreendimentos hidrelétricos. As fitofisionomias encontradas são divididas em campestres, savânicas e florestais ${ }^{(6)}$.

Para a descrição da distribuição da raiva animal nos municípios da microrregião Quirinópolis, foram analisados os relatórios do Setor de Raiva do Laboratório de Análise e Diagnóstico Veterinário - LABVET, referentes ao período de 1990 a 2010, contendo informações sobre os resultados de exames realizados pelas técnicas de Imunofluorescência Direta (IFD) e Inoculação Intracerebral em Camundongos (IC), os quais se constituíram nos dados primícios do presente estudo.

Um banco de dados foi estruturado com recursos do pacote estatístico do programa Microsoft Excel $^{\odot} 2007$, no qual foram registradas, para cada exame, as variáveis município de origem do animal, espécie animal, resultado, mês e ano. O banco de dados foi organizado agrupando-se todos 
os municípios da microrregião estudada em pastas dentro de uma mesma planilha. Cada pasta continha nas linhas os meses da série cronológica e em colunas os resultados do exame laboratorial para bovinos, equinos, suínos, morcegos hematófagos e não hematófagos. Tais dados corresponderam aos números de diagnósticos laboratoriais total, negativos e positivos para raiva desses cinco grupos animais por mês, ano e municípios correspondentes.

A distribuição temporal dos diagnósticos confirmados da raiva bovina, equina, suína, de morcegos hematófagos e não hematófagos foi representada, segundo SAMPAIO ${ }^{(7)}$, por meio de tabelas e curvas de tendência, sendo as informações estruturadas no mesmo programa, que também foi utilizado para confecção dos gráficos correspondentes e cálculo das equações de tendência linear.

\section{Resultados}

No período de 1990 a 2010, 116 amostras de sistema nervoso central (SNC) de diferentes espécies animais (bovina, ovina, equina, morcegos hematófagos e não hematófagos), provenientes dos nove municípios da microrregião Quirinópolis, foram enviadas ao Laboratório de Análise e Diagnóstico Veterinário - LABVET. Do total de 116 amostras analisadas neste período, dez (9\%) foram positivas para o vírus rábico. Todos os resultados positivos foram provenientes de SNC de bovinos. A distribuição espacial dos diagnósticos laboratoriais da raiva animal foi avaliada anualmente nos nove municípios da microrregião Quirinópolis e esteve presente em quatro (Tabela 1). O município de Itarumã foi o que apresentou maior número de casos diagnosticados de raiva, com seis amostras positivas (33\%) dentre as 18 enviadas para análise nos anos de 2002 e 2005. Por outro lado, o município de Caçu foi o responsável pelo envio de 37 amostras, seguido de Quirinópolis com 24 amostras enviadas, tendo apresentado no período analisado 5,4 e 4,1\% amostras positivas, respectivamente. Os municípios de Itajá, Cachoeira Alta, São Simão e Gouvelândia não apresentaram resultados positivos para as amostras enviadas. Não houve envio de amostras pelo município de Lagoa Santa durante os anos analisados (Tabela 1).

Tabela 1: Amostras enviadas e amostras positivas para raiva animal na microrregião Quirinópolis, Goiás, Brasil, entre 1990 e 2010

\begin{tabular}{lcc}
\hline Município & Examinados & Positivos \\
\hline Caçu & 37 & 2 \\
Itarumã & 18 & 6 \\
Quirinópolis & 24 & 1 \\
Paranaiguara & 1 & 1 \\
Cachoeira Alta & 13 & 0 \\
São Simão & 12 & 0 \\
Itajá & 10 & 0 \\
Gouvelândia & 1 & 0 \\
Lagoa Santa & 0 & 0 \\
\hline Total & $\mathbf{1 1 6}$ & $\mathbf{1 0}$ \\
\hline
\end{tabular}

Em 21 anos de diagnóstico, apenas em 1994, 2002, 2005 e 2009, foram obtidos resultados positivos para as amostras enviadas (Figura 2), com uma média de 2,5 amostras positivas para os quatro anos em questão. 


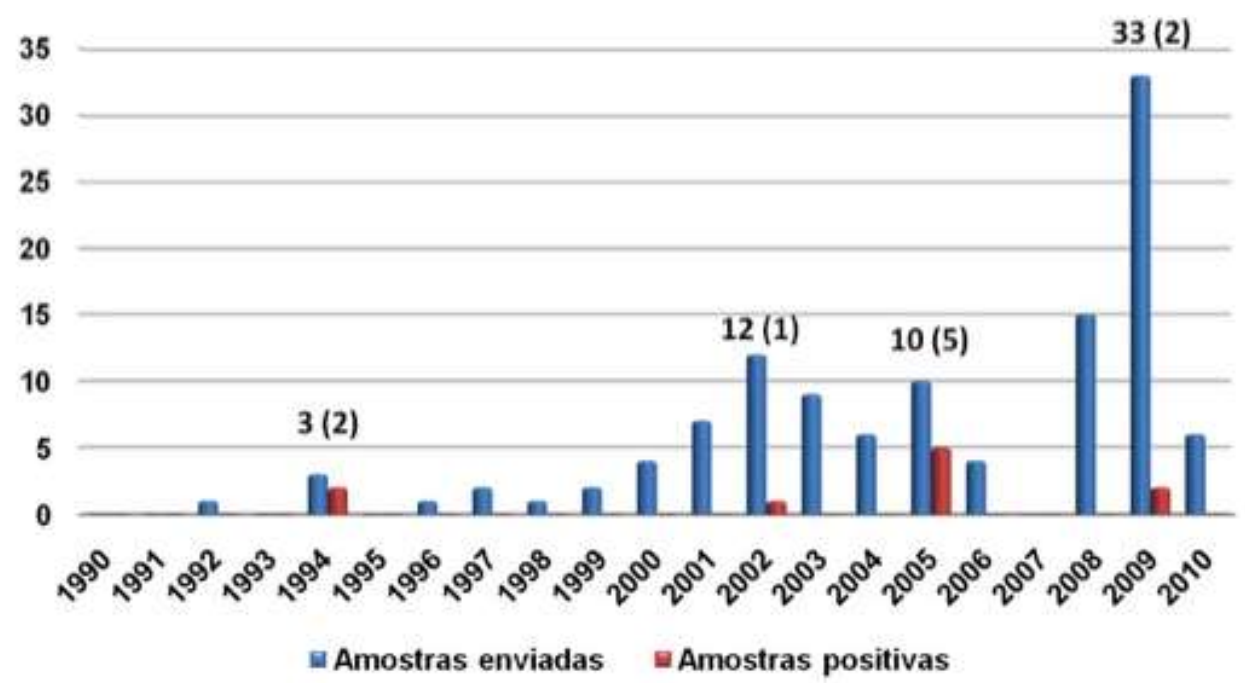

Figura 2: Número de amostras positivas para vírus rábico na Microrregião Quirinópolis, Goiás, Brasil, por ano, na série cronológica 1990-2010

Com relação à frequência na remessa de amostras para diagnóstico, houve tendência de aumento e, consequentemente, elevação do número de exames laboratoriais enviados e realizados, principalmente para bovinos e morcegos hematófagos (Figura 3).

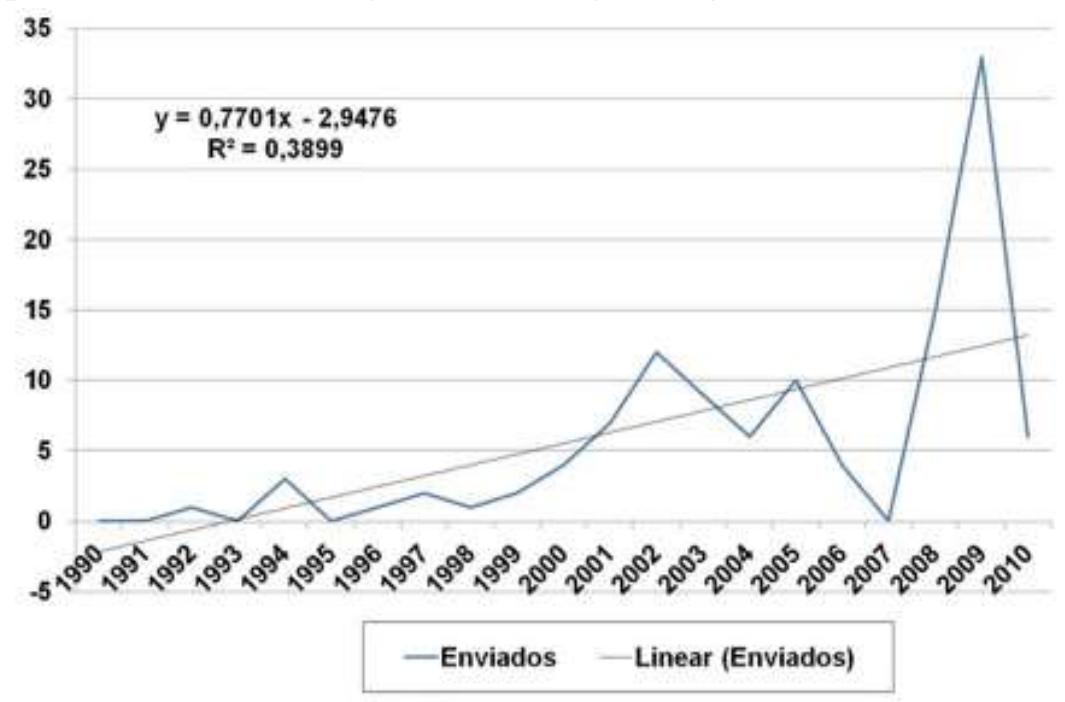

Figura 3: Evolução do envio de amostras para diagnóstico de raiva animal na microrregião Quirinópolis, Goiás, Brasil, entre 1990 e 2010

Quanto ao número de casos de raiva animal, também houve tendência ao aumento de diagnósticos positivos (Figura 4), com registros positivos apenas para a espécie bovina. 


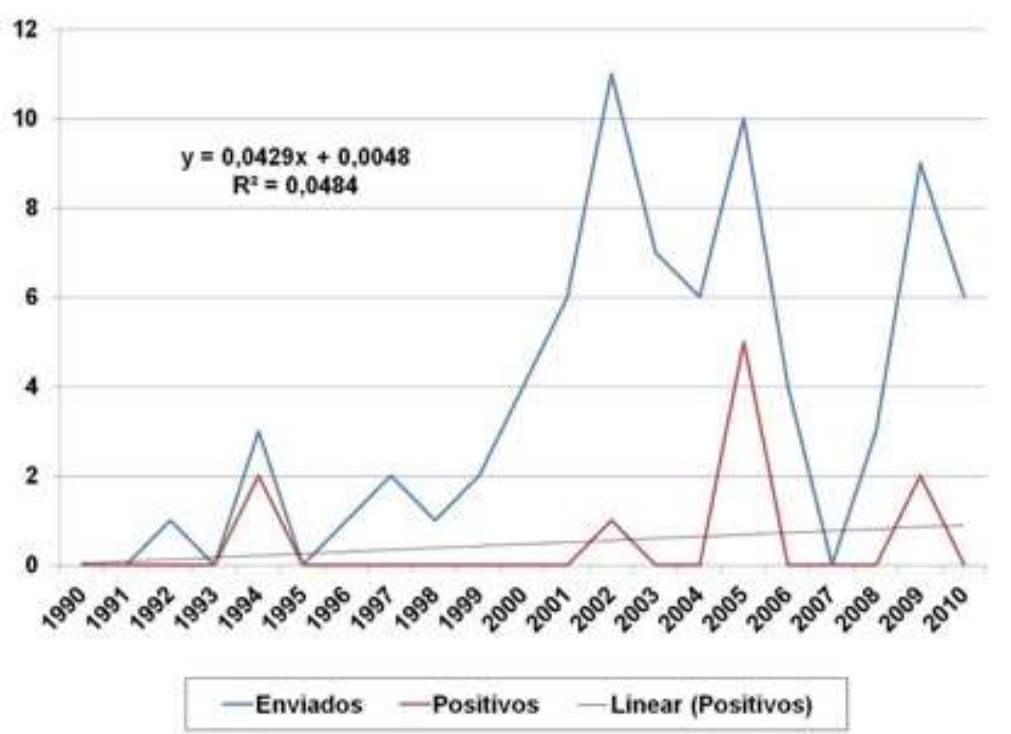

Figura 4: Avaliação de diagnósticos positivos para a espécie bovina, na microrregião Quirinópolis, Goiás, Brasil, entre 1990 e 2010.

A espécie bovina correspondeu àquela com maior número de amostras analisadas, com 76 (65\%) exemplares, seguido de morcegos hematófagos com 36 (31\%). Para morcegos não hematófagos e ovinos foram enviadas três $(3 \%)$ e uma (1\%) amostra, respectivamente (Figura 5). Não houve amostras enviadas de equídeos e suínos para análise de vírus rábico na série cronológica avaliada.

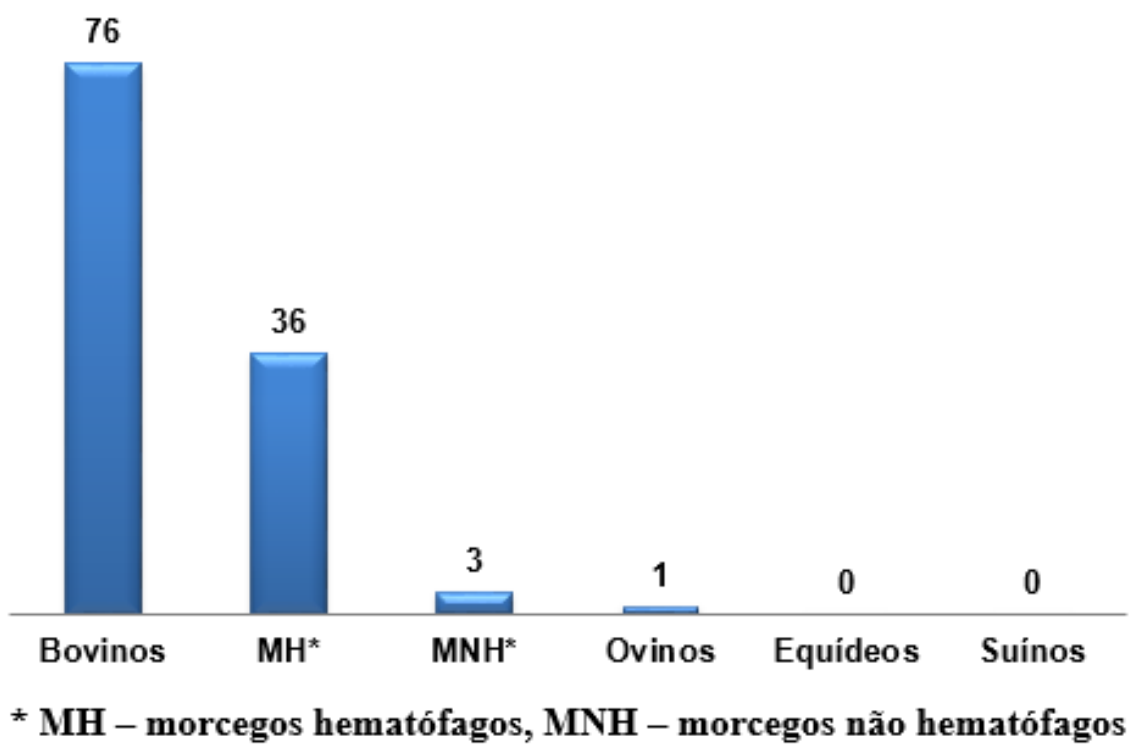

Figura 5: Número de amostras, por espécie animal, analisadas para diagnóstico laboratorial da raiva na Microrregião de Quirinópolis, Goiás, Brasil, na série cronológica 1990-2010

O número mensal de exames laboratoriais no período analisado variou de quatro exames no mês de janeiro a 32 no mês de outubro. Fevereiro, junho e julho também mantiveram resultados acima da média, com 10, 14 e 10 amostras enviadas, respectivamente. Na Figura 6 está demonstrada tal variação no período, destacando-se que, apesar de ocorrerem aumento e redução de envio de 
amostras durante o ano para pesquisa de vírus rábico no período estudado, ao se analisar a média e o desvio-padrão $(\mu=9,7 ; \sigma=7,6)$, pôde-se inferir que não houve um período com aumento ou diminuição expressivo de envio de amostras para pesquisa de vírus rábico.

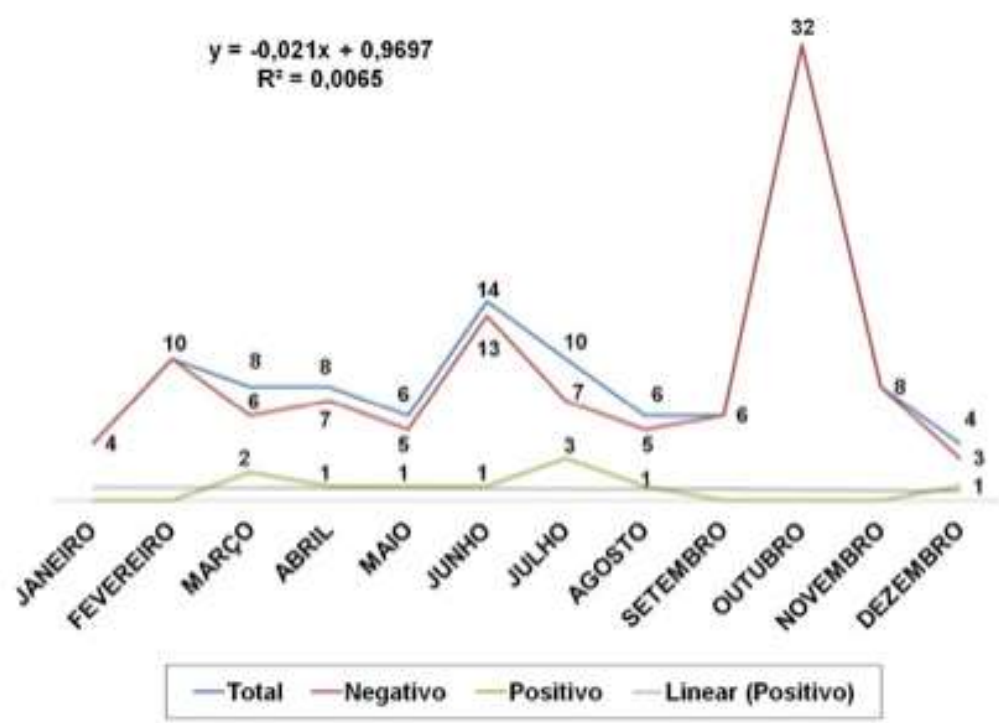

Figura 6: Distribuição mensal dos exames laboratoriais para a raiva animal na série cronológica 1990-2010, na microrregião Quirinópolis, Goiás, Brasil

Quanto aos resultados positivos, não se observou maior variação, oscilando entre um a três exames $(\mu=1,4 ; \sigma=0,8)$, estando distribuídos em apenas sete meses, mantendo-se constante (Figura 6).

Com relação à estação do ano, do total de casos positivos, cinco casos ocorreram no inverno, quatro no outono e um no verão. Apesar de não ter sido observado nenhum caso positivo na primavera, o maior número de amostras foi enviado nesta estação (Figura 7).

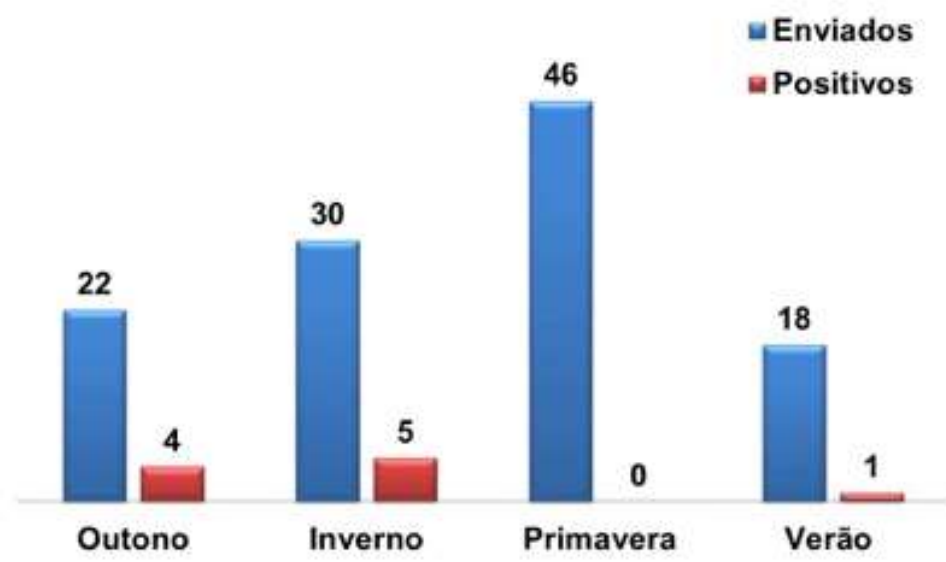

Figura 7: Número de amostras enviadas e resultados positivos dos casos de raiva bovina diagnosticados em 1990-2010 na microrregião Quirinópolis, Goiás, Brasil, de acordo com a estação do ano 


\section{Discussão}

Com os resultados apresentados pode-se afirmar que houve um aumento no envio de amostras para análise desta microrregião, já que nos últimos três anos avaliados foram enviadas 54 (47\%) amostras para análise, ou seja, quase a metade de todas as amostras enviadas nos 21 anos de estudo. Em relação às amostras provenientes de bovinos, houve, na última década, aumento considerável em relação à década anterior, com 62 amostras enviadas, isto é, $82 \%$ em relação ao total de amostras de bovinos enviadas para análise de vírus rábico no período avaliado (Figura 4). Consequentemente, houve aumento no número de exames laboratoriais realizados (Figura 3), assim como tendência ao aumento de diagnósticos positivos (Figura 4).

Tal elevação do número de exames de raiva bovina já havia sido observada por Jayme ${ }^{(8)}$, ao detectar a tendência crescente de diagnósticos positivos da doença no estado de Goiás nas décadas de 1970 a 1990. A autora associa tal fato à antropização ambiental, à melhoria do sistema de vigilância epidemiológica, à ampliação do atendimento veterinário de campo e ao aprimoramento de laboratórios para a realização de exames pelos órgãos governamentais.

Santos et al. ${ }^{(9)}$, em um estudo no estado de Goiás no espaço temporal de 1976-2001, também mostraram que os casos de raiva foram aumentando no decorrer dos anos, com uma positividade de $67,5 \%$ em bovinos para as amostras analisadas pelo LABVET no ano de 2001. Esses dados estimularam a criação de uma Instrução Normativa (IN) na qual são estabelecidas regiões de alto e baixo risco para a raiva dos herbívoros em Goiás e que obriga a vacinação antirrábica para bovídeos, equídeos, ovinos e caprinos nas regiões definidas como de alto risco, ficando as regiões de baixo risco apenas com a vigilância epidemiológica ${ }^{(10)}$. No entanto, essa IN não explica quais critérios são utilizados para estabelecer essas regiões, apenas cita quais são os municípios classificados como de alto e baixo risco. Logo, é necessário um estudo com o objetivo de uma nova configuração das áreas de risco no estado de Goiás.

Pondera-se, entretanto, que a obrigatoriedade da vacinação antirrábica para bovídeos, equídeos, ovinos e caprinos nas regiões definidas como de alto risco não impede a disseminação do VR para áreas limítrofes, com outra classificação e, portanto, sem vacinação obrigatória, o que pode implicar em ocorrência de casos. Por outro lado, segundo o Programa Nacional de Controle da Raiva dos Herbívoros, o qual analisou os resultados dos relatórios do Setor de Raiva em cada estado no Brasil, entre 2002 a 2012, no estado de Goiás os casos de raiva em herbívoros e suínos caíram quase $100 \%{ }^{(11)}$.

No Mato Grosso, no período de 1996 a 2006, Matta et al. ${ }^{(12)}$ relataram um aumento na ocorrência dos casos de raiva notificados ao longo do período estudado. Como o estado de Mato Grosso possui o maior rebanho bovino do Brasil, uma área territorial de quase um milhão de quilômetros quadrados e três biomas diferenciados, a implementação de medidas profiláticas mais efetivas contra a raiva foi indicada no estudo.

Em Minas Gerais, houve uma tendência decrescente para diagnósticos positivos nos exames de raiva bovina realizados no estado pelos órgãos competentes de 1998 a 2006, o que apontou para a melhoria do controle da raiva bovina e para a diminuição dos casos clínicos da doença; entretanto, não se pode descartar a possibilidade d eesta diminuição estar relacionada ao não envio de material para laboratórios por parte dos veterinários ${ }^{(13)}$. 
No Mato Grosso do Sul, com efetivo bovino aproximado de 23 milhões e uma frequência de diagnósticos de raiva de $13 \%$ de todos os casos diagnosticados em bovinos, estima-se que morram 149.500 bovinos anualmente ${ }^{(14)}$. Esse número de animais mortos por raiva pode ser ainda maior, já que o autor não considerou em seu estudo 131 casos $(9,16 \%)$ diagnosticados como meningoencefalite e que não apresentavam corpúsculos de inclusão.

$\mathrm{Na}$ Paraíba, Lima et al. ${ }^{(14)}$ relataram $18,75 \%$ de positividade e destacaram ser a raiva a enfermidade neurológica mais frequentemente diagnosticada. Tal condição sinaliza para a alta perda de animais na região, superior à observada em outros estados, como no Rio Grande do Sul, que tem um percentual de bovinos mortos por raiva de $2,5 \%^{(15)}$ a $2,7 \%^{(16)}$. No entanto, segundo os autores essa maior frequência de raiva em bovinos na Paraíba em relação aos estados citados anteriormente deve-se, provavelmente, entre outras causas, ao fato de que nesses estados são realizadas campanhas de controle de morcegos, o que não acontece na Paraíba.

Segundo Gomes ${ }^{(17)}$, a maior fonte de infecção do vírus da raiva para bovinos são os morcegos hematófagos, porque no Brasil a variante de vírus isolada em bovinos é a mesma isolada de $D$. Rotundus $^{(2)}$. Segundo esses autores, já foram isolados vírus rábico em outros animais como raposas (Dusicyon vetulus), demonstrando que esse animal no Nordeste é considerado um reservatório silvestre importante do vírus da raiva. Outras variantes já foram isoladas em saguis no Ceará ${ }^{(18)}$ e em outra espécie de raposa (Pseudoalopex vetulus) na Paraíba ${ }^{(19)}$, enfatizando que esses animais também podem estar envolvidos na manutenção da doença ${ }^{(17,20)}$.

Deve-se considerar que os dados de outros estados comentados anteriormente são apenas estimativas e não dados oficiais, ou seja, aqueles que são notificados ao Serviço Oficial de Defesa Sanitária Animal, e que, no Brasil, esses dados oficiais são registrados em publicações oficiais no site do Ministério da Agricultura, Pecuária e Abastecimento - MAPA. Apesar do alto número de casos de raiva observado nesses estados, observa-se um declínio discreto nos casos de raiva em herbívoros no país, principalmente em bovídeos, porém pequeno para uma doença que é totalmente prevenível, sendo a vacinação indicada ou até obrigatória em algumas regiões.

Mesmo sendo os dados dos estados citados anteriormente apenas estimativas, ao se extrapolar esses dados para todo o Brasil, com uma população de 195 milhões de bovinos, pode-se estimar que no país morram, anualmente, 842.688 bovinos $^{(14)}$. Tais estimativas são muito superiores às 40.000 perdas anuais notificadas, citadas por Heinemann et al. ${ }^{(2)}$, indicando o baixo envio de amostras e a subnotificação, o que pode resultar no desconhecimento do número de bovinos que vem a óbito devido à raiva dos herbívoros.

No caso do estado de Goiás, a Agência Goiana de Defesa Agropecuária (AGRODEFESA) foi criada sem, no entanto, haver previsão inicial dos seus cargos, tendo sido apenas transferidos para a autarquia aqueles servidores que exerciam o serviço de defesa agropecuária na Agência Rural, a qual executou a atividade de defesa agropecuária de 1999 a 2003. Com a criação da AGRODEFESA, só foi realizado concurso para provimento de cargos em 2010. Assim, tais condições, que resultam em baixo efetivo de médicos veterinários, muitos dos quais responsáveis pela coleta e envio de material para diagnóstico da raiva, podem refletir nos baixos níveis de envio de amostras e na subnotificação no período analisado.

Os morcegos hematófagos foram a segunda espécie com maior número de amostras analisadas, com $35 \%$ (Figura 5), provavelmente pelo grande número de exemplares enviados para análise em outubro de 2009 pelo município de Caçu. Esses resultados corroboram os observados por Tomaz ${ }^{(21)}$, nos quais os morcegos hematófagos foram representados em 32,21\% das amostras. Porém, no 
presente estudo, acredita-se que este aumento no envio de amostras tenha ocorrido devido à construção de uma usina hidrelétrica localizada no município de Caçu, que se iniciou em 2007 e foi concluída em 2010. Geralmente, na implantação de usinas hidrelétricas, são realizados monitoramento e resgate de fauna para enchimento dos reservatórios.

O aumento nos números de casos de raiva em morcegos hematófagos e não hematófagos tem sido observado, assim como o número de morcegos submetidos a diagnóstico em todo país. De acordo com Teixeira et al. ${ }^{(16)}$, isso provavelmente reflete o aumento do conhecimento sobre o papel dos morcegos no ciclo de transmissão da raiva ou ainda pela maior oportunidade de percepção da presença da espécie no meio ambiente alterado pelo homem.

No Brasil, das 167 espécies de morcegos encontradas, o vírus rábico já foi isolado de 41 espécies ${ }^{(22)}$. Nos ambientes urbanos, o VR tem sido identificado em diversas espécies de morcegos, hematófagos e não hematófagos, representando um risco à saúde pública, uma vez que muitos apresentam hábitos sinantrópicos. Contudo, o morcego hematófago D.rotundus é considerado o principal hospedeiro do vírus rábico sendo responsável pela infecção direta de animais domésticos e eventualmente de seres humanos ${ }^{(23)}$.

Além disso, os morcegos hematófagos distribuem-se amplamente do sul do México ao norte da Argentina e têm interferido no ciclo aéreo de transmissão da doença, com inúmeros casos em espécies não hematófagas ${ }^{(24-26)}$, além do ciclo urbano, transmitindo a raiva a cães e gatos ${ }^{(27)}$.

Com o rápido crescimento urbano, os morcegos têm colonizado novos nichos ecológicos e deixado seus abrigos noturnos para ocupar ambientes construídos pelo homem. A alteração da natureza com a consequente diminuição dos recursos naturais tem levado os morcegos hematófagos a procurar novas alternativas alimentares, como os humanos ${ }^{(8,28)}$, tornando-os como opções alternativas de alimento aos morcegos hematófagos, sendo procuradas como fontes de alimento somente na ausência de bovinos. Entretanto, essa alternativa alimentar amplia a introdução e disseminação da zoonose.

Na América Latina, os ataques de morcegos hematófagos a humanos são influenciados diretamente pelas ações humanas como a remoção ou realocação do gado, a ocupação desordenada dos ambientes, como no desmatamento, na mineração, na construção de hidrelétricas, usinas e rodovias, sem contar na oferta de abrigos que essas ações do homem desencadeiam como túneis, pontes e construções abandonadas.

A raiva diagnosticada em morcegos não hematófagos vem sendo registrada desde as décadas de 80 e 90, quando Uieda et al. ${ }^{(29)}$ descreveram quatro casos positivos para a raiva diagnosticados em morcegos insetívoros. Em seu estudo, os autores destacaram as espécies de morcegos que utilizam os recursos fornecidos pelo homem, direta ou indiretamente, como algumas plantas utilizadas na arborização como abrigos diurnos e/ou noturnos e outras como alimento, as edificações também usadas como abrigos diurnos e a iluminação pública noturna das cidades que atrai insetos que são habitualmente consumidos por diversas espécies de morcegos insetívoros.

Queiroz et al. ${ }^{(30)}$ descreveram a epidemiologia da raiva na região Noroeste do estado de São Paulo no período de 1993 a 2007, observando que, de um total de 518 amostras diagnosticadas como positivas, 50 (10\%) foram de morcegos. A maioria (70\%) dos casos foi registrada em morcegos insetívoros, seguido dos frugívoros (30\%), sendo que nenhum caso foi diagnosticado em morcegos hematófagos. Observaram também que $12 \%$ (6/50) dos morcegos positivos para raiva, tiveram algum tipo de contato direto ou agressão a pessoas ou animais. A presença de morcegos entre os 
animais agressores também foi observada em outro estudo no estado de São Paulo, conduzido por Buso et al. ${ }^{(31)}$, no mesmo intervalo de tempo, representando $8,1 \%$.

Segundo Tomaz ${ }^{(21)}$, a menor proporção de exames para equinos e suínos pode sugerir a ocorrência de outras doenças de sintomatologia nervosa, porém a ausência de dados epidemiológicos dificulta uma análise da real situação. Os resultados de $\operatorname{Tomaz}^{(21)}$ juntamente com os aqui apresentados alinham-se com os de Santos et al. ${ }^{(9)}$, que observaram uma falha na documentação dos casos de raiva em suínos no estado de Goiás.

A distribuição dos casos de raiva positivos diagnosticados no período de 1990-2010 em relação à época do ano foi maior no inverno e no outono, ou seja, correspondente às épocas de seca na região analisada. O critério de análise sazonal pelas quatro estações é o mais encontrado na literatura; entretanto, para a microrregião em estudo, as características climáticas observadas dividem-se em seca (outono e inverno) e chuvosa (primavera e verão), constituindo dois períodos climáticos bem definidos e não quatro estações. Apesar desta distinção, o padrão de ocorrência foi o mesmo havendo correspondência com o citado na literatura.

Embora a raiva possa ocorrer em qualquer época do ano, os resultados aqui apresentados corroboram os de Marcolongo-Pereira et al. ${ }^{(32)}$ na Região Sul do Rio Grande do Sul, onde os surtos foram mais frequentes no outono, embora tenham ocorrido em todas as estações do ano. No Mato Grosso do Sul também já foi mencionada tendência da raiva ser sazonal com o maior número de casos no outono. Segundo esses autores, esse fato seria devido ao ciclo biológico do morcego, cujo acasalamento ocorre na primavera, período no qual há aumento da transmissão do vírus entre as colônias e o pico de surtos ocorreria no outono em função do período de incubação da doença nos morcegos e nos bovinos agredidos.

Em levantamentos realizados na região central do Rio Grande do Sul, o maior número de casos foi observado na primavera e verão ${ }^{(33)}$. Tal quadro respalda o observado por Jayme ${ }^{(8)}$, em Goiás, de 1970-2001, sugerindo uma concentração de diagnósticos laboratoriais positivos no período chuvoso, ou seja, de outubro a março, período das estações primavera e verão.

Pondera-se, neste estudo, que o maior número de exames realizados em outubro esteja relacionado diretamente ao envio de morcegos hematófagos oriundos do município de Caçu ao laboratório, em 2009 (17/116), não estando vinculada à suspeita da doença.

Segundo Lima et al. ${ }^{(14)}$ a raiva pode ocorrer em qualquer época do ano, confirmando o observado por Tomaz ${ }^{(21)}$, que não encontrou diferença significativa no número de diagnósticos positivos ao longo do ano, para a microrregião Porangatu, Goiás, na série histórica 1999-2008.

O compromisso com o uso ordenado de áreas do Cerrado é fundamental para preservação e conservação de sua biodiversidade, principalmente no estado de Goiás, o qual tem suas fitofisionomias substituídas por monoculturas como a cana-de-açúcar, alterando o habitat natural dos morcegos. Assim, são fundamentais o desenvolvimento de estudos e a realização de procedimentos que resultem na redução do risco de transmissão da raiva aos animais domésticos e aos seres humanos por morcegos. Para tanto, torna-se importante o conhecimento da ecologia dos morcegos, sua distribuição e seu controle estratégico, e da epidemiologia da enfermidade em cada região do País, incluindo análise de sua evolução espaço-temporal nas diversas espécies de animais domésticos. 


\section{Conclusões}

Dentre as amostras de SNC enviadas para análise do VR, poucas foram positivas para a microrregião Quirinópolis. Os resultados negativos podem ser explicados pelo baixo número de amostras enviadas para realização de exames de raiva no período analisado ou pela melhoria do sistema de vigilância epidemiológica.

Em relação aos municípios avaliados anualmente para a distribuição espacial dos diagnósticos laboratoriais da raiva animal, apenas metade possui resultados positivos para o VR, mesmo sem o envio de amostras pelo município de Lagoa Santa. O município de Itarumã foi o que apresentou o maior número de casos diagnosticados de raiva no período estudado.

Em 21 anos de diagnóstico, apenas 1994, 2002, 2005 e 2009 apresentam registros de resultados positivos para as amostras enviadas, sendo o maior número de amostras enviadas da espécie bovina. Observa-se tendência de aumento tanto do envio de amostras quanto de número de exames laboratoriais e, consequentemente, tendência ao aumento de diagnósticos positivos.

A distribuição dos casos positivos em relação à época do ano é maior no período da seca, embora a raiva possa ocorrer em qualquer época do ano.

\section{Referências}

1.Acha PN. Epidemiology of paralytic rabies and bat rabies. Boletín de la Oficina Internacional de Epizootias, 1967:67:343-382.

2.Heinemann FM, Fernandes-Matioli FMC, Cortez A, Soares RM, Sakamoto SM, Bernardi F, Ito FH, Madeira AMBN, Richtzenhain LJ. Genealogical analysis of rabies virus strain from Brazil based on N gene alleles. Archive of Epidemiology and Infection. 2002;128:503-511.

3.De Deus GT, Becer M, Navarro IT. Diagnóstico da raiva em morcegos não hematófagos na cidade de Campo Grande, Mato Grosso do Sul, Centro Oeste do Brasil: descrição de casos. Semina: Ciências Agrárias. 2003;24(1):171-176.

4.Johnson N, Vos A, Freuling C, Tordo N, Fooks AR, Müller T. Human rabies due to lyssavirus infection of bat origin. Veterinary Microbiology, 2010:142:151-159.

5.SIEG. Sistema Estadual de Estatística de Informações Geográficas de Goiás, 2006. Available from: http://www.sieg.go.gov.br

6.Ribeiro JF, Walter BMT. As Principais Fitofisionomias de Cerrado. In: Sano SM, Almeida SP De, Ribeiro JF. Cerrado: ecologia e flora. Embrapa Cerrados. Brasília-DF: Embrapa Informação Tecnológica; 2008. p. 152-212. Vol.1. Portuguese.

7.Sampaio IBM. Estatística aplicada à experimentação animal. 2. ed. Belo Horizonte: Fundação de Estudos e Pesquisas em Medicina Veterinária e Zootecnia; 2002. 265 p. Portuguese.

8.Jayme VS. A modificação do espaço agrário e a dinâmica da raiva bovina em Goiás, Brasil, 1970-2001. 2003. 264f. Tese (Doutorado em Medicina Veterinária) - Escola de Veterinária, Universidade Federal de Minas Gerais, Belo Horizonte, MG.Portuguese. 
9.Santos MFC, Resende RM, Sobrinho RN, Vieira S. Diagnóstico laboratorial da raiva no Estado de Goiás no período de 1976 a 2001. Ciência Animal Brasileira. 2006;7(1):77-83.

10.Goiás. Instrução Normativa $N^{\circ}$ 001/2005, de 21 de fevereiro de 2005. Goiás: Agência Goiana de Defesa Agropecuária, 2005. Available from: http://www.agrodefesa.go.gov.br/index.php/publicacoes/sanidadeanimal/programas/135-in-001-agrodefesa/file Portuguese.

11.Brasil. Divisão de Epidemiologia / Departamento de Saúde Animal - DSA/ SDA/ Mapa. Ações de controle da raiva dos herbívoros no Brasil. 2013. [cited 2013 jul 13]. Available from: http://www.agricultura.gov.br/arq_editor/file/Aniamal/programa\%20nacional\%20dos\%20herbivoros/Dados \%20controle\%20raiiva\%20herb\%C3\%ADvoros\%20Brasi1\%20ate\%202012.pdf Portuguese.

12.Matta GCA, Nociti DLP, Carvalho AAB, Samara SI, Ito FH, Sakai T, Itou T, Sato G, Kobayashi Y, Mochizuki N. Caracterização genética e distribuição geográfica do vírus rábico isolado de bovinos no estado de Mato Grosso, Brasil. Arquivos do Instituto Biológico. 2010;77(1):19-24.

13.Menezes FL, Silva JÁ,Moreira EC, Meneses JNC, Magalhães DF, Barbosa AD, Oliveira CSF. Distribuição espaço-temporal da raiva bovina em Minas Gerais, 1998 a 2006. Arquivo Brasileiro de Medicina Veterinária e Zootecnia. 2008;60(3):566-573.

14.Lima EF, Riet-Correa F, Castro RS, Gomes AAB, Lima FS. Sinais clínicos, distribuição das lesões no sistema nervoso e epidemiologia da raiva em herbívoros na região Nordeste do Brasil. Pesquisa Veterinária Brasileira. 2005;25(4):250-264.

15.Sanches AWD, Langohr IM, Stigge AL, Barros CSL. Doenças do sistema nervoso central em bovinos no sul do Brasil. Pesquisa Veterinária Brasileira. 2000;20(3):113-118.

16.Teixeira TF, Holz CL, Caixeta SPMB, Dezen D, Cibulski SP, Silva JR, Rosa JCA, Schmidt E, Ferreira JC, Batista HBCR, Caldas E, Franco AC, Roehe PM. Diagnóstico de raiva no Rio Grande do Sul, Brasil, de 1985 a 2007. Pesquisa Veterinária Brasileira. 2008;28(10):515-520.

17.Barros JS, Freitas CEAA, Sousa FS. Raiva em animais silvestres no Estado do Ceará particularmente na raposa (Dusicyon vetulus). Zoon. Rev. Int. 1989:1(1):9-13.

18.Morais NB, Rolim BN, Chaves HHM, Brito-Neto J, Silva LM. Rabies in tamarins (Callithrix jacchus) in the State of Ceará, Brazil, a distinct viral variant? Memórias do Instituto Oswaldo Cruz. 2000;95(5):609-610.

19.Silva MLCR, Lima FS, Gomes AAB, Azevedo SS, Alves CJ, Bernardi F, Ito FH. Isolation of rabies vírus from the parotid salivary glands of foxes (Pseudalopex vetulus) from Paraíba State, Northeastern, Brazil. Brazilian Journal of Microbiology. 2009;40:446-449.

20.Bernardi F, Nadin-Davis SA, Wandeler AI, Armstrong J, Gomes AAB, Lima FS, Nogueira FRB, Ito FH. Antigenic and genetic characterization of rabies viruses isolated from domestic and wild animals of Brazil identifies the hoary fox as a rabies reservoir. Journal of General Virology 2005;86:3153-3162.

21.Tomaz LAG. Dinâmica espaço-temporal da raiva animal e bioecologia de quirópteros na microrregião de Porangatu, Goiás, Brasil. 2009. 150f. Tese (Doutorado em Medicina Veterinária) - Curso de Pós-graduação em Ciência Animal, Universidade Federal de Goiás, GO. Available from: http://ppgca.evz.ufg.br/uploads/67/original_Tese2009_Leonardo_Tomaz.pdf Portuguese.

22.Sodré MM, Gama AR, Almeida MF. Updated list of bat species positive for rabies in Brazil. Revista Instituto Medicina Tropical São Paulo. 2010;52(2):75-81.

23.BATISTA, H. B. C. R.; FRANCO, A. C.; ROEHE, P. M. Raiva: uma breve revisão. Acta Scientiae Veterinariae, 2007;35: (2):125-144. 
24.Souza LC, Langoni H, Silva RC, Lucheis SB. Vigilância epidemiológica da raiva na região de BotucatuSP: importância dos quirópteros na manutenção do vírus na natureza. Ars Veterinária. 2005;21(1):62-68.

25.Scheffer KC, Carrieri ML, Albas A, Santos HCP, Kotait I, Ito FH. Vírus da raiva em quirópteros naturalmente infectados no Estado de São Paulo, Brasil. Revista Saúde Pública. 2007;41(3):389-95.

26.Albas A, Souza EAN, Lourenço RA, Favoretto SR, Sodré MM. Perfil antigênico do vírus da raiva isolado de diferentes espécies de morcegos não hematófagos da Região de Presidente Prudente, Estado de São Paulo. Revista Sociedade Brasileira Medicina Tropical. 2009;42(1):15-17.

27.Batista HBCR, Caldas E, Junqueira DM, Teixeira TF, Ferreira JC, Silva JR, Rosa JCA, Roehe PM. Canine rabies in Rio Grande do Sul caused by an insectivorous bat rabies virus variant. Acta Scientiae Veterinariae. 2009;37(4):371-374.

28.Dantas-Torres F. Bats and their role in human rabies epidemiology in the Americas. Journal Venominous Animals Toxins Tropical Disease. 2008;14(2):194-203.

29.Uieda W, Harmani NMS, Silva MMS. Raiva em morcegos insetívoros (Molossidae) do Sudeste do Brasil. Revista Saúde Pública. 1995;29(5):393-397.

30.Queiroz LH, Carvalho C, Buso DS, Ferrari CLI, Pedro WA. Perfil epidemiológico da raiva na Região Noroeste do Estado de São Paulo no período de 1993 a 2007. Revista Sociedade Brasileira Medicina Tropical. 2009;42:9-14.

31.Buso DS, Nunes CM, Queiroz LH. Características relatadas sobre animais agressores submetidos ao diagnóstico de raiva, São Paulo, Brasil, 1993-2007. Cadernos Saúde Pública. 2009;25(12):2747-2751.

32.Marcolongo-Pereira C, Sallis ESV, Grecco FB, Raffi MB, Soares MP, Schild AL. Raiva em bovinos na Região Sul do Rio Grande do Sul: epidemiologia e diagnóstico imuno-histoquímico. Pesquisa Veterinária Brasileira. 2011;31(4):331-335.

33.Rissi DR, Pierezan F, Kommers GD, Barros CSL. Ocorrência de raiva em ovinos no Rio Grande do Sul. Pesquisa Veterinária Brasileira. 2008;28(10):495-500. 